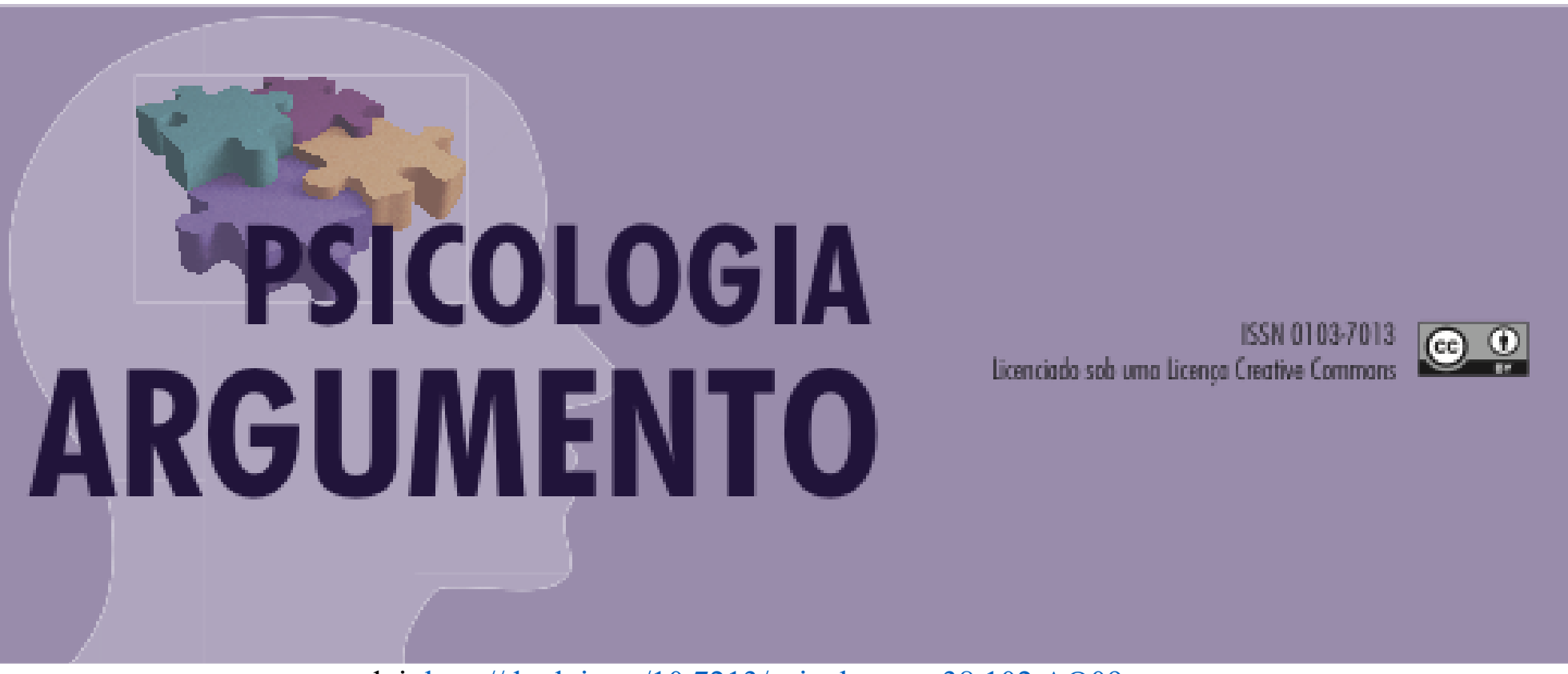

doi: http://dx.doi.org/10.7213/psicolargum.38.102.AO09

\title{
Percepção de casais que vivenciaram perda gestacional sobre o apoio social
}

Perception of couples who experienced pregnancy loss about social support

Percepción de parejas que experimentaron pérdida de embarazo sobre el apoyo social

\author{
Marina Camargo Barth \\ Universidade Federal de Ciências da Saúde de Porto Alegre; barthcmarina@gmail.com \\ ORCID 0000-0003-3645-9553 \\ Gabriela Vescovi \\ Universidade Federal do Rio Grande do Sul; gabriela.vescovi@gmail.com \\ ORCID 0000-0001-6747-8744 \\ Daniela Centenaro Levandowski \\ Universidade Federal de Ciências da Saúde de Porto Alegre; dclevandowski@gmail.com \\ ORCID 0000-0002-6338-7287
}

\begin{abstract}
A perda gestacional é uma vivência inesperada de intensa carga emocional. O luto dela decorrente, muitas vezes não reconhecido socialmente, pode repercutir sobre o apoio aos casais. Esse estudo investigou a percepção de casais que vivenciaram perda gestacional sobre o apoio social. Examinou-se a satisfação e os tipos de apoio recebido, bem como o ajustamento conjugal. Doze casais heterossexuais brasileiros foram entrevistados e responderam à Escala Revisada de Ajustamento Diádico (R-DAS). Cônjuge, família, terapia e grupos de mães online foram mencionados como fontes de apoio emocional, material/de serviço e de regulação/controle social. Constatou-se tanto satisfação como insatisfação quanto às diferentes fontes e tipos de apoio recebidos. A insatisfação foi mais enfatizada, embora restrita a menos fontes. A satisfação referiuse a situações mais pontuais e foi proveniente de fontes variadas. Evidenciou-se a relevância do
\end{abstract}


apoio emocional frente à perda gestacional, o que exige ampliação da discussão social e qualificação dos profissionais.

Palavras-chave: Aborto espontâneo; Apoio social; Luto.

\begin{abstract}
Pregnancy loss is an unexpected experience of intense emotional charge. The resulting grief, often not socially recognized, can have an impact on support for couples. This study investigated the perception of couples who experienced pregnancy loss about social support. Satisfaction and type of support received were examined, as well as marital adjustment. Twelve heterosexual Brazilian couples were interviewed and filled the Revised Dyadic Adjustment Scale (R-DAS). Spouse, family, therapy and online groups of mothers were mentioned as sources of emotional, material/service support and social regulation/control. Both satisfaction and dissatisfaction were found in relation to different sources and types of support received. Dissatisfaction was more emphasized, although restricted to fewer sources. Satisfaction referred to more specific situations and different sources. The relevance of emotional support in the face of pregnancy loss became evident, which requires broadening of the social discussion and professionals' qualification.
\end{abstract}

Keywords: Spontaneous abortion; Social support; Bereavement.

\title{
Resumen
}

Lá pérdida del embarazo es una experiencia inesperada de intensa carga emocional. El duelo resultante, a menudo no reconocido socialmente, puede tener un impacto en el apoyo a las parejas. Este estudio investigó la percepción de las parejas que experimentaron pérdida del embarazo sobre el apoyo social. La satisfacción y los tipos de apoyo recibidos, así como el ajuste matrimonial, fueron examinados. Doce parejas brasileñas heterosexuales fueron entrevistadas y respondieron a la Escala Revisada de Ajuste Matrimonial (R-DAS). Cónyuge, familia, terapia y grupos de madres en línea fueron mencionados como fuentes de apoyo emocional, ayuda material/de servicio y regulación/control social. Tanto la satisfacción como la insatisfacción fueron identificadas com respecto a las diferentes fuentes y tipos de apoyo recibidos. La insatisfacción fue más enfatizada, aunque limitada a menos fuentes. La satisfacción se ha referido a situaciones más especificas y a diferentes fuentes de apoyo. La relevancia del apoyo emocional ante la pérdida del embarazo se hizo evidente, lo que requiere ampliar la discusión social y la calificación de los profesionales.

Palabras clave: Aborto espontáneo; Apoyo social; Aflicción.

\section{Introdução}

A perda gestacional (PG) é considerada uma vivência inesperada de intensa carga emocional para os envolvidos (Camarneiro, Maciel, \& Silveira, 2015). Este evento acarreta a dissolução de desejos e fantasias e interrompe o exercício concreto da parentalidade (Muza, Souza, Arrais, \& Iaconelli, 2013). O processo de luto decorrente dessa perda tende a ser confuso e ambíguo; é comum a ausência de uma compreensão precisa acerca do objeto perdido (Rios, Santos, \& Dell'Aglio, 2016), tanto pelos enlutados 
quanto pelas pessoas com quem se relacionam. Dessa forma, esse tipo de perda acaba resultando, muitas vezes, em um processo de luto não reconhecido socialmente (Worden, 2013).

As pessoas em geral não reconhecem a PG enquanto uma perda por entenderem que os pais ainda não construíram um vínculo importante com o filho (Camarneiro et al., 2015) e que o sofrimento decorrente dela não seria tão intenso, pois a relação perdida poderia ser facilmente substituída. Contudo, investigações com casais que passaram por essa situação constatam sofrimento intenso (Muza et al., 2013).

A negação social do luto parental pode impactar na qualidade e quantidade de apoio recebido pelos casais e potencializar emoções como raiva, culpa, medo e vergonha (Rios et al., 2016). Além disso, pode dificultar a solicitação de apoio por parte deles, repercutindo a nível individual, conjugal e familiar (Camarneiro et al., 2015).

Apesar de o apoio social ser definido e avaliado de forma plural na literatura científica (Gonçalves, Pawlowski, Bandeira, \& Piccinini, 2011), no presente estudo adota-se as premissas da Teoria da Rede Social Pessoal (Sluzki, 2003). O autor considera relevante identificar três dimensões do apoio social: quem fornece o apoio (fonte), os tipos de suporte fornecido pela rede (funções da rede) e a avaliação subjetiva do apoio recebido. Para Sluzki, a rede de apoio é composta pelas relações que a pessoa julga importantes para si, significativas e diferenciadas em relação às demais. Essas relações são classificadas como íntimas (incluem familiares em contato direto e amigos próximos), pessoais com menor grau de compromisso (relações sociais e profissionais) e ocasionais (estabelecidas com conhecidos da escola/trabalho, vizinhos e familiares distantes). Em relação às funções da rede, Sluzki (2003) aponta: a) Companhia social (prática de atividades em conjunto, "estar junto"); b) Apoio emocional (atitude emocional positiva, incluindo compreensão, empatia, simpatia e estímulo); c) Guia cognitivo e de conselhos (partilha de informações pessoais ou sociais, elucidando expectativas e viabilizando modelos de papéis); d) Regulação/controle social (reafirmação de papéis e responsabilidades, normalizando os desvios comportamentais); e) Ajuda material e de serviço (qualquer auxílio físico, incluindo colaboração de especialistas, como por exemplo, terapeutas e agentes de saúde mental); e f) Acesso a novos contatos (proporcionar ligação com pessoas que até então não faziam parte da rede social do indivíduo). 
A rede de apoio de um indivíduo costuma ser acionada em situações de sofrimento, tais como a perda de um ente querido (Sluzki, 2003). O enfrentamento da perda é um processo singular, influenciado pelo contexto de vida, pela cultura (Santos et al., 2017), pelo tipo de perda sofrida (Worden, 2013) e pelo apoio recebido (Muza et al., 2013). Entretanto, não é possível estabelecer a priori um parâmetro de apoio suficiente diante de uma perda (Worden, 2013).

Homens e mulheres sofrem diante de uma PG, embora esse sofrimento varie quanto ao início, duração e intensidade (Mourão, 2016). A literatura também aponta particularidades no enfrentamento da PG por homens e mulheres, que podem gerar obstáculos para a relação conjugal, como a percepção feminina de dificuldade na comunicação com o parceiro e o desejo de que eles expressem mais seus sentimentos (Mourão, 2016). Estudos demonstram a insatisfação das mulheres que viveram uma PG com o apoio recebido, em diferentes contextos (Miranda, 2016; Muza et al., 2013). É comum entre elas a busca de ajuda espiritual e apoio junto a outras mulheres que já sofreram PG (Quitans, 2018).

Contar com o apoio de fontes externas (família ampliada, amigos e profissionais de saúde) é essencial. O uso de estratégias de coping variadas e a presença de recursos conjugais, familiares e da rede social auxiliam no manejo das tarefas do luto e na prevenção do luto complicado (Lari, Shimo, Carmona, De Moraes, \& Campos, 2018).

\section{Objetivos}

Diante da importância do tema, esse estudo objetivou investigar a percepção de casais que vivenciaram uma PG sobre o apoio social. Particularmente, buscou examinar as fontes de apoio, os tipos de apoio recebido pelos casais e sua satisfação com o mesmo, bem como avaliar o ajustamento conjugal.

\section{Método}

\section{Participantes}

Doze casais heterossexuais predominantemente residentes em Minas Gerais $(\mathrm{n}=05)$. A idade das mulheres variou de 26 a 50 anos e a dos homens, de 29 a 58 anos. A maior parte dos casais não tinha filhos vivos $(n=07)$ e dois estavam gestando no momento da pesquisa. Quanto à religião, 29,1\% $(\mathrm{n}=07)$ dos entrevistados consideram-se católicos 
e, em relação à classe social, predominou a classe $D(n=04)$. Características sociodemográficas e de saúde dos casais estão detalhadas na Tabela 1.

Apurou-se um total de 35 PG, sendo que metade dos casais $(n=06)$ sofreu mais de uma perda. A maioria das perdas $(n=23)$ ocorreu até a $10^{a}$ semana de gestação. Os casais acessaram, no momento da PG, na maioria das vezes, hospitais particulares $(n=09)$ e clínicas de ecografia e obstetrícia $(\mathrm{n}=05)$.

Predominou a percepção de bom ajustamento conjugal entre os participantes. Discrepâncias na percepção dos cônjuges foram observadas em apenas dois casais (Casal 5 e 12); em ambos, os homens apresentaram percepção negativa e as mulheres, positiva.

Tabela 1 - Dados sociodemográficos e de saúde dos participantes

\begin{tabular}{|c|c|c|c|c|c|c|c|}
\hline $\begin{array}{l}\text { Identificação } \\
\text { e Idade (anos) }\end{array}$ & Estado & Escolaridade & Religião & $\begin{array}{l}\text { Situação } \\
\text { parental }\end{array}$ & Perdas & $\begin{array}{c}\text { Serviços } \\
\text { acessados }\end{array}$ & R-Das \\
\hline $\begin{array}{l}\text { 1) Jack (42) e } \\
\text { Rose (40) }\end{array}$ & $\mathrm{MG}$ & $\begin{array}{c}\text { Jack: EMC } \\
\text { Rose: PGrad }\end{array}$ & $\begin{array}{c}\text { Jack: } \\
\text { nenhuma } \\
\text { Rose: } \\
\text { Espírita }\end{array}$ & $\begin{array}{l}\text { Um filho } \\
\text { pós-PG }\end{array}$ & $\begin{array}{c}3 \text { PG }(18,6 \\
\text { e } 24 \text { sem })\end{array}$ & $\begin{array}{l}\text { CEO e } \\
\text { HPub } \\
\text { (última } \\
\text { PG) }\end{array}$ & $\begin{array}{c}\text { Ambos: } \\
\text { BOM }\end{array}$ \\
\hline $\begin{array}{l}\text { 2) Bonnie (50) } \\
\text { e Clyde (58) }\end{array}$ & $\mathrm{RS}$ & $\begin{array}{c}\text { Clyde: ESC } \\
\text { Bonnie: PGrad }\end{array}$ & $\begin{array}{l}\text { Clyde: } \\
\text { Nenhuma } \\
\text { Bonnie: } \\
\text { Espírita }\end{array}$ & $\begin{array}{l}\text { Um filho } \\
\text { pós-PG } \\
\text { (Bonnie: } \\
\text { FRA) }\end{array}$ & $\begin{array}{l}16 \text { PG após } \\
\text { inseminação/ } \\
\text { fertilização } \\
\text { (primeiras } \\
\text { sem) }\end{array}$ & CRA & $\begin{array}{c}\text { Ambos: } \\
\text { BOM }\end{array}$ \\
\hline $\begin{array}{l}\text { 3) Eduardo } \\
\text { (36) e Mônica } \\
\text { (38) }\end{array}$ & $\mathrm{MG}$ & $\begin{array}{l}\text { Eduardo: EMI } \\
\text { Mônica: ESI }\end{array}$ & $\begin{array}{c}\text { Ambos: } \\
\text { Evangélica }\end{array}$ & $\begin{array}{l}\text { SFV em } \\
\text { comum } \\
\text { (Eduardo: } \\
\text { FRA) }\end{array}$ & $\begin{array}{c}2 \text { PG } \\
(35 \text { e } 6 \text { sem })\end{array}$ & $\begin{array}{c}\text { CEO e } \\
\text { HPart } \\
\text { (leito; PS) }\end{array}$ & $\begin{array}{c}\text { Ambos: } \\
\text { BOM }\end{array}$ \\
\hline $\begin{array}{c}\text { 4) Marco } \\
\text { Antônio (36) } \\
\text { e Cleópatra } \\
(31)\end{array}$ & RJ & $\begin{array}{c}\text { Marco } \\
\text { Antônio: ESC } \\
\text { Cleópatra: } \\
\text { PGrad }\end{array}$ & $\begin{array}{c}\text { Marco } \\
\text { Antônio: } \\
\text { nenhuma } \\
\text { Cleóprata: } \\
\text { Espírita }\end{array}$ & SFV & $\begin{array}{c}1 \mathrm{PG} \\
(6 \mathrm{sem})\end{array}$ & $\begin{array}{l}\text { HPart } \\
\text { (exames; } \\
\text { PS) }\end{array}$ & $\begin{array}{c}\text { Ambos: } \\
\text { BOM }\end{array}$ \\
\hline $\begin{array}{l}\text { 5) John (29) e } \\
\text { Yoko (37) }\end{array}$ & $\mathrm{MG}$ & $\begin{array}{c}\text { John: ESI } \\
\text { Yoko: ESC }\end{array}$ & $\begin{array}{l}\text { Ambos: } \\
\text { Nenhuma }\end{array}$ & $\begin{array}{l}\text { SFV em } \\
\text { comum } \\
\text { (Yoko: } \\
\text { FRA) }\end{array}$ & $\begin{array}{c}1 \mathrm{PG} \\
(29 \text { sem) }\end{array}$ & $\begin{array}{c}\text { CEO e } \\
\text { HPart } \\
\text { (leito; PS) }\end{array}$ & $\begin{array}{l}\text { John: } \\
\text { RUIM } \\
\text { Yoko: } \\
\text { BOM }\end{array}$ \\
\hline $\begin{array}{l}\text { 6) Juan (47) e } \\
\text { Evita (36) }\end{array}$ & PR & $\begin{array}{l}\text { Juan: PGrad } \\
\text { Evita: ESC }\end{array}$ & $\begin{array}{c}\text { Juan: Deus } \\
\text { Evita: } \\
\text { Nenhuma }\end{array}$ & SFV & $\begin{array}{c}2 \mathrm{PG} \\
(7 \mathrm{e} 11 \mathrm{sem})\end{array}$ & $\begin{array}{c}\text { CEO e } \\
\text { HPart } \\
\text { (leito; PS) }\end{array}$ & $\begin{array}{c}\text { Ambos: } \\
\text { BOM }\end{array}$ \\
\hline $\begin{array}{c}\text { 7) Giuseppe } \\
\text { (39) e Anita } \\
\text { (34) }\end{array}$ & RS & $\begin{array}{l}\text { Giuseppe: } \\
\text { ESC Anita: } \\
\text { ESC }\end{array}$ & $\begin{array}{l}\text { Ambos: } \\
\text { C. } \\
\text { S.Últimos } \\
\text { Dias }\end{array}$ & $\begin{array}{l}\text { Dois filhos } \\
\text { anteriores } \\
\text { às PG. } \\
\text { Gestante. }\end{array}$ & $\begin{array}{c}1 \mathrm{PN} \\
(12 \text { sem após } \\
\text { nascimento) } \\
1 \mathrm{PG} \\
(10 \mathrm{sem})\end{array}$ & $\begin{array}{c}\text { HPart } \\
\text { (leito; PS) }\end{array}$ & $\begin{array}{l}\text { Ambos: } \\
\text { BOM }\end{array}$ \\
\hline $\begin{array}{l}\text { 8) Pierre (36)) } \\
\text { e Marie (36) }\end{array}$ & SP & $\begin{array}{c}\text { Pierre: ESI } \\
\text { Marie: PGrad }\end{array}$ & $\begin{array}{l}\text { Ambos: } \\
\text { Católica }\end{array}$ & $\begin{array}{c}\text { SFV } \\
\text { Gestante. }\end{array}$ & $\begin{array}{c}2 \mathrm{PG} \\
(8 \mathrm{e} 12 \mathrm{sem})\end{array}$ & $\begin{array}{l}\text { Médico PS } \\
\text { e dois } \\
\text { HPart } \\
\text { (leito; PS) }\end{array}$ & $\begin{array}{c}\text { Ambos: } \\
\text { BOM }\end{array}$ \\
\hline
\end{tabular}


Continuação Tabela 1.

\begin{tabular}{|c|c|c|c|c|c|c|c|}
\hline $\begin{array}{l}\text { Identificação } \\
\text { e Idade (anos) }\end{array}$ & Estado & Escolaridade & Religião & $\begin{array}{l}\text { Situação } \\
\text { parental }\end{array}$ & Perdas & $\begin{array}{c}\text { Serviços } \\
\text { acessados }\end{array}$ & R-Das \\
\hline $\begin{array}{l}\text { 9) Bentinho } \\
\text { (31) e Capitu } \\
\text { (26) }\end{array}$ & $\mathrm{RS}$ & $\begin{array}{c}\text { Bentinho: } \\
\text { EMC Capitu: } \\
\text { EMC }\end{array}$ & $\begin{array}{l}\text { Ambos: } \\
\text { Católica }\end{array}$ & SFV & $\begin{array}{c}1 \mathrm{PG} \\
(13 \mathrm{sem})\end{array}$ & $\begin{array}{c}\text { HPart } \\
\text { leito; PS) }\end{array}$ & $\begin{array}{l}\text { Ambos: } \\
\text { BOM }\end{array}$ \\
\hline $\begin{array}{l}\text { 10) Rodrigo } \\
\text { (33) e Bibiana } \\
\text { (30) }\end{array}$ & MG & $\begin{array}{l}\text { Rodrigo: EMI } \\
\text { Bibiana: EMC }\end{array}$ & $\begin{array}{l}\text { Rodrigo: } \\
\text { Católica } \\
\text { Bibiana: } \\
\text { Evangélica } \\
\text { Desviada }\end{array}$ & SFV & $\begin{array}{c}3 \mathrm{PG} \\
(15,2 \text { e } 21 \\
\text { sem })\end{array}$ & $\begin{array}{l}\text { HPart } \\
\text { (leito; PS), } \\
\text { HPub e } \\
\text { posto de } \\
\text { saúde }\end{array}$ & $\begin{array}{l}\text { Ambos: } \\
\text { BOM }\end{array}$ \\
\hline $\begin{array}{l}\text { 11) Lampião } \\
\text { (41) e Maria } \\
\text { Bonita (28) }\end{array}$ & MG & $\begin{array}{l}\text { Lampião: ESI } \\
\text { Maria Bonita: } \\
\text { ESI }\end{array}$ & $\begin{array}{l}\text { Ambos: } \\
\text { Espírita }\end{array}$ & $\begin{array}{l}\text { Filho } \\
\text { anterior à } \\
\text { PG } \\
\text { (Lampião: } \\
\text { FRA) }\end{array}$ & $\begin{array}{c}1 \mathrm{PG} \\
\text { (no parto às } \\
35 \mathrm{sem} \text { ) }\end{array}$ & $\begin{array}{l}\text { CEO e } \\
\text { HPub }\end{array}$ & $\begin{array}{l}\text { Ambos: } \\
\text { BOM }\end{array}$ \\
\hline $\begin{array}{l}\text { 12) Romeu } \\
\text { (37) e Julieta } \\
\text { (37) }\end{array}$ & $\mathrm{RS}$ & $\begin{array}{l}\text { Romeu: EMC } \\
\text { Julieta: PGrad }\end{array}$ & $\begin{array}{l}\text { Ambos: } \\
\text { Católica }\end{array}$ & SFV & $\begin{array}{c}1 \mathrm{PG} \\
(25 \mathrm{sem})\end{array}$ & $\begin{array}{c}\text { HPart } \\
\text { (leito: PS) }\end{array}$ & $\begin{array}{l}\text { Romeu: } \\
\text { RUIM } \\
\text { Julieta: } \\
\text { BOM }\end{array}$ \\
\hline \multicolumn{8}{|c|}{$\begin{array}{l}\text { Legenda: } \mathrm{PG}=\text { Perda gestacional. } \mathrm{PN}=\text { Perda Neonatal EMC = Ensino Médio completo. EMI = Ensino } \\
\text { Médio incompleto. ESC = Ensino Superior completo. PGrad = Pós-Graduação. SFV = Sem filhos vivos. } \\
\text { FRA = Filho de relacionamento anterior. } \mathrm{PG}=\text { Perda gestacional. Sem }=\text { Semanas. CEO = Clínica de } \\
\text { ecografia obstétrica. } \text { CRA = Centro de reprodução assistida. HPart }=\text { Hospital particular. HPub }=\text { Hospital } \\
\text { público. PS = Plano de saúde. }\end{array}$} \\
\hline
\end{tabular}

\section{Delineamento, Instrumentos e Procedimentos de Coleta de Dados}

Trata-se de estudo qualitativo, de caráter transversal, descritivo e comparativo (Creswell, 2010), derivado de dados coletados em um projeto de pesquisa sobre resiliência familiar (SUPRIMIDO1). O convite para participação foi divulgado de forma online nos perfis de integrantes da equipe de pesquisa em redes sociais e de ONGs que atuam na temática da PG. Os casais que demonstraram interesse em participar foram acessados de forma presencial ou virtual, via Skype.

Em ambas as modalidades de coleta foram aplicados os instrumentos a seguir em um único encontro, com duração aproximada de 90 minutos: 1) Ficha de Dados Sociodemográficos e Clínicos (adaptada de Núcleo de Infância e Família - NUDIF, 2008), para caracterizar o casal e suas famílias, investigando conjuntamente aspectos como escolaridade, ocupação, renda, histórico de doenças, a PG, etc.; 2) Escala Revisada de Ajustamento Diádico (Revised Dyadic Adjustment Scale - R-DAS, Busby, Christensen, Crane, \& Larson, 1995), versão em português brasileiro (Hernandez, 2008), para avaliar individualmente o apoio intraconjugal a partir de três dimensões de ajustamento diádico (consenso, coesão e satisfação). A consistência interna da R-DAS com casais norteamericanos com e sem sofrimento conjugal foi de 0.90 (0.81 em Consenso, $0.85 \mathrm{em}$ Satisfação e 0.80 em Coesão; Busby et al., 1995). A versão em português (Hernandez, 
2008), após validação fatorial e de critério, foi considerada uma medida confiável e válida para uso em estudos brasileiros; e 3) Entrevista sobre os processos-chave da resiliência familiar em situações de PG (SUPRIMIDO2), de caráter semiestruturado, elaborada com base nos processos-chave da resiliência familiar propostos por Walsh (2016), para avaliar conjuntamente, dentre outros aspectos, a rede de apoio e o apoio social recebido/buscado pelos casais. As entrevistas foram gravadas em áudio para posterior transcrição. Realizouse uma coleta piloto para avaliar a adequação e a necessidade de ajustes dos instrumentos. Procedimentos de Análise dos Dados e Considerações Éticas

A R-DAS foi levantada conforme as instruções dos autores. As entrevistas foram transcritas com o auxílio do software InqScribe para posterior análise no programa NVivo. Empregou-se a técnica codebook (Braun, Clarke, Hayfield, \& Terry, 2019) para análise. Os dados foram categorizados com base nos conceitos da Teoria da Rede Social Pessoal (Sluzki, 2003), que originaram as categorias temáticas: fontes de suporte, funções da rede (tipos de suporte) e avaliação subjetiva do apoio (satisfação/insatisfação). Quanto à percepção sobre o apoio social, foram considerados, na fala dos participantes, os adjetivos usados por eles para caracterizar as experiências positivas (satisfação com apoio) e negativas (insatisfação com apoio) quanto ao suporte recebido. Duas avaliadoras realizaram a codificação dos dados de forma independente e cega, com base nessa estrutura de temas. Dúvidas foram dirimidas por discussão e o processo de alocação foi revisado por uma terceira avaliadora. Os dados da R-DAS foram triangulados com os demais achados (Creswell, 2010) para ampliar a compreensão do tema em estudo.

O projeto do qual o presente estudo deriva foi aprovado pelo Comitê de Ética em Pesquisa da Universidade (Parecer número 2.341.006) e está de acordo com as Resoluções 510/2016 e 466/12 do Conselho Nacional de Saúde. O Termo de Consentimento Livre e Esclarecido foi apresentado a todos os participantes, que permaneceram com uma via (física ou eletrônica). A coleta de dados foi conduzida por uma psicóloga, que realizou acolhimento aos casais em momentos de maior desconforto emocional. Estabeleceu-se acordo com uma clínica de Psicologia na cidade em que ocorreram coletas presenciais para eventuais encaminhamentos. Aos participantes acessados à distância, disponibilizou-se novo contato com a entrevistadora para suporte emocional e/ou auxílio na busca de serviços de psicoterapia. 


\section{Resultados}

A Tabela 2 apresenta, para cada fonte de apoio, a avaliação subjetiva dos casais (satisfação/insatisfação), os tipos de apoio recebidos (funções da rede) e uma vinheta de fala para exemplificação. Após, segue a discussão dos achados.

Tabela 2: Resultados da análise de acordo com as fontes de apoio, avaliação subjetiva, funções da rede e vinhetas ilustrativas

\begin{tabular}{|c|c|c|c|}
\hline $\begin{array}{l}\text { Fontes de apoio } \\
\text { e classificação }\end{array}$ & $\begin{array}{c}\text { Avaliação subjetiva } \\
\text { do apoio }\end{array}$ & Funções da rede & Vinhetas \\
\hline $\begin{array}{l}\text { Cônjuge } \\
\text { (Íntima) }\end{array}$ & Satisfação & $\begin{array}{l}\text { Apoio emocional* } \\
\text { Regulação/controle } \\
\text { social } \\
\text { Companhia social }\end{array}$ & $\begin{array}{l}\text { "É o casal mesmo que se apoia, } \\
\text { porque passou junto, dividiu os } \\
\text { mesmos sonhos, as mesmas } \\
\text { angústias" (Rose, C1) }\end{array}$ \\
\hline \multirow{2}{*}{$\begin{array}{l}\text { Família } \\
\text { (Íntima) }\end{array}$} & Satisfação & $\begin{array}{l}\text { Apoio emocional } \\
\text { Ajuda material e de } \\
\text { serviço } \\
\text { Companhia social* }\end{array}$ & $\begin{array}{l}\text { "A gente quis ficar perto da } \\
\text { família (...) passava temporada na } \\
\text { casa da minha sogra, na casa dos } \\
\text { meus pais (...) sempre tinha gente } \\
\text { na nossa casa" (Yoko, C5) }\end{array}$ \\
\hline & Insatisfação & Falta de apoio emocional & $\begin{array}{c}\text { "Familia às vezes quer ajudar, } \\
\text { mas infelizmente acaba trazendo } \\
\text { até uns questionamento que dói""' } \\
\text { (Clyde, } \mathrm{C} 2)\end{array}$ \\
\hline \multirow{2}{*}{$\begin{array}{c}\text { Amigos/ } \\
\text { Conhecidos } \\
\text { (Íntima/Menor } \\
\text { grau de } \\
\text { compromisso) }\end{array}$} & Satisfação & $\begin{array}{l}\text { Apoio Emocional* } \\
\text { Companhia Social }\end{array}$ & $\begin{array}{l}\text { "Essas horas tu vê o quanto as } \\
\text { pessoas gostam de ti. Tu pode } \\
\text { contar com as pessoas (...) nessa } \\
\text { hora que tu vê como tu tem } \\
\text { amigos" (Julieta, C12) }\end{array}$ \\
\hline & Insatisfação & $\begin{array}{l}\text { Falta de apoio emocional } \\
\text { Falta de } \\
\text { regulação/controle social }\end{array}$ & $\begin{array}{c}\text { "As pessoas evitam conversar } \\
\text { com a gente, tem gente que ainda } \\
\text { acha que a gente nem é pai, nem é } \\
\text { mãe" (Eduardo, } \mathrm{C} 3)\end{array}$ \\
\hline $\begin{array}{l}\text { Grupo online } \\
\text { de mães } \\
\text { (Ocasional) }\end{array}$ & Satisfação & $\begin{array}{l}\text { Apoio Emocional } \\
\text { Acesso a novos contatos } \\
\text { Guia cognitivo/de } \\
\text { conselhos* }\end{array}$ & $\begin{array}{c}\text { "A gente compartilhava a dor, } \\
\text { dava dicas, conversava sobre a } \\
\text { terapia (...) ajudou nesse ponto, } \\
\text { compartilhar momentos" } \\
\text { (Mônica, C3) }\end{array}$ \\
\hline \multirow{2}{*}{$\begin{array}{c}\text { Pessoas do } \\
\text { meio religioso } \\
\text { (Comunitária e } \\
\text { ocasional) }\end{array}$} & Satisfação & Apoio Emocional & $\begin{array}{l}\text { "Nos apoiou muito nossos amigos } \\
\text { da igreja (...) foi muito importante } \\
\text { esse acolhimento" (Anita, C7) }\end{array}$ \\
\hline & Insatisfação & Falta de apoio emocional & $\begin{array}{l}\text { "O pastor da igreja acabou se } \\
\text { distanciando" (Eduardo, } \mathrm{C} 3 \text { ) }\end{array}$ \\
\hline $\begin{array}{l}\text { Psicoterapia } \\
\text { (Serviço e } \\
\text { ocasional) }\end{array}$ & Satisfação & $\begin{array}{l}\text { Apoio Emocional } \\
\text { Guia cognitivo/de } \\
\text { conselhos } \\
\text { Ajuda material/de } \\
\text { serviço* }\end{array}$ & $\begin{array}{l}\text { "Melhorou MUITO... a terapia } \\
\text { que me fez ter outra visão das } \\
\text { coisas assim" (Capitu, C9) }\end{array}$ \\
\hline \multirow{2}{*}{$\begin{array}{l}\text { Profissionais } \\
\text { da saúde } \\
\text { (Serviço e } \\
\text { ocasional) }\end{array}$} & Satisfação & $\begin{array}{l}\text { Apoio Emocional } \\
\text { Ajuda material/de } \\
\text { serviço }\end{array}$ & $\begin{array}{c}\text { "No caso do médico, foi bom (...) } \\
\text { ele realmente é um cara bem } \\
\text { humanizado, ele tem um } \\
\text { diferencial" (Juan, C6) }\end{array}$ \\
\hline & Insatisfação & $\begin{array}{l}\text { Falta de ajuda } \\
\text { material/de serviço } \\
\text { Falta de apoio } \\
\text { emocional* }\end{array}$ & $\begin{array}{c}\text { "Ele não ligou nem pra saber } \\
\text { como ela tava, então isso deixou a } \\
\text { gente bem chateado" (Bentinho, } \\
\text { C9) }\end{array}$ \\
\hline
\end{tabular}


Continuação Tabela 2

\begin{tabular}{|c|c|c|c|}
\hline $\begin{array}{l}\text { Fontes de apoio } \\
\text { e classificação }\end{array}$ & $\begin{array}{c}\text { Avaliação subjetiva } \\
\text { do apoio }\end{array}$ & Funções da rede & Vinhetas \\
\hline \multirow{2}{*}{$\begin{array}{c}\text { Colegas de } \\
\text { trabalho } \\
\text { (Comunitária) }\end{array}$} & Satisfação & $\begin{array}{l}\text { Apoio Emocional* } \\
\text { Regulação/controle } \\
\text { social }\end{array}$ & $\begin{array}{c}\text { "O gerente lá, o pessoal me } \\
\text { apoiou bastante, me deram a } \\
\text { folga pra 'mim' ficar com ela" } \\
\text { (Rodrigo, } \mathrm{C} 10)\end{array}$ \\
\hline & Insatisfação & Falta de apoio emocional & $\begin{array}{l}\text { "Ninguém sabia no meu local de } \\
\text { trabalho o que tava se passando } \\
\text { (..) pra não ter que ouvir várias } \\
\text { opiniões, eu preferia não } \\
\text { comentar" (Bonnie, C2) }\end{array}$ \\
\hline
\end{tabular}

Legenda: $\mathrm{C}=$ Casal; $(*)=$ Identifica a função da rede ilustrada pela vinheta

\section{Discussão}

A principal fonte de apoio para todos os casais foi o cônjuge (citado por todos os participantes), que é parte de uma relação considerada íntima (Sluzki, 2003). Os resultados da R-DAS alinham-se a isso, pois predominou a percepção de bom nível de ajustamento conjugal para ambos os membros do casal $(n=10)$. A literatura aponta a relação conjugal como essencial no enfrentamento da PG (Bellhouse, Temple-Smith, \& Bilardi, 2018), pela compreensão mútua decorrente do compartilhamento da experiência (Quitans, 2018). Entretanto, estudos recentes (Bellhouse et al., 2018; McGee, PettyJohn, \& Gallus, 2018) não encontraram unanimidade entre as mulheres em relação à percepção positiva de apoio do cônjuge, ao contrário do presente estudo. Essa discrepância pode derivar da modalidade de coleta de dados adotada, pois, nos estudos mencionados, as mulheres foram entrevistadas individualmente, enquanto que aqui foi realizada uma entrevista conjunta com o casal. De qualquer forma, esses achados concordam com investigações (McGee et al., 2018; Quitans, 2018) que também destacaram o apoio do cônjuge como imprescindível para o enfrentamento da PG.

A literatura aponta diferenças entre mulheres e homens no enfrentamento da PG (Bellhouse et al., 2018), como evidenciado no presente estudo. Os homens desempenharam o papel de apoio e não expressaram tanto quanto as mulheres sua dor e tristeza. Já elas demonstraram maior facilidade para conversar sobre a PG, o que foi percebido na condução das entrevistas.

Evidenciou-se também a percepção de uma suposta "força" dos homens, enquanto as mulheres se viram mais fragilizadas diante da PG $(n=7)$. A necessidade masculina de demonstrar força foi identificada em outros estudos, que indicaram um desejo de proteger e cuidar da companheira nesse momento (Chavez, Handley, Jones, Eddy, \& Poll, 2019). 
Koert e colaboradores (2018) também encontraram um sentimento de pressão para demonstrar otimismo e encontrar soluções no momento da PG, talvez pela crença cultural de que os homens devem resguardar os próprios sentimentos para cuidar da companheira (Quitans, 2018), escondendo a própria vulnerabilidade (Carneiro, Rodrigues, \& Alves 2017).

Muitas decisões e responsabilidades relativas à PG ficaram a cargo dos homens (como mencionado por oito casais), configurando uma ajuda material e de serviço (Sluzki, 2003). Em muitos casos isso decorreu do fato de as mulheres estarem internadas, o que limitou sua capacidade de decisão. A literatura indica que, diante da PG, os homens são instigados a se comportar de maneira mais "instrumental", isto é, para solucionar problemas (Quitans, 2018).

Os achados da R-DAS também destacaram, em dois casais, diferenças entre homens e mulheres. Em ambos, os escores masculinos foram inferiores aos femininos, indicando percepção menos positiva de ajustamento conjugal. Esse achado pode estar relacionado ao fato de esses participantes, em seus discursos, verbalizarem a preferência por não falar sobre o tema. Apesar das diferenças, a maioria dos casais relatou a existência de apoio mútuo $(n=9)$, o que pode ser pensado em função de o impacto emocional da perda refletir em ambos (Lemos \& Cunha, 2015; Quitans, 2018). Os participantes também relataram uma maior união e proximidade após a PG $(n=5)$, caracterizando apoio emocional, o que corrobora achados de estudos recentes (Chavez et. al., 2019; McGee et al., 2018; Quitans, 2018). Outro tipo de apoio fornecido pelo cônjuge foi a companhia social, o "estar junto" $(n=2)$, especialmente durante os procedimentos médicos. Esse tipo de suporte foi fornecido, na maioria das vezes, pela presença física e diálogo. Essa postura de diálogo contribui para conectar os homens à vivência da PG e evitar o afastamento conjugal (Chavez et al., 2019).

Outra fonte de apoio citada por todos os casais foi a família, também mencionada em outras pesquisas (Lemos \& Cunha, 2015). Alguns casais $(n=3)$ perceberam que a PG fortaleceu esses vínculos. Pais e irmãos foram frequentemente mencionados $(n=8)$. Na maioria das vezes, os casais se sentiram acolhidos através da companhia social $(n=8)$, isto é, pelo acompanhamento diário na residência e/ou no hospital.

Os entrevistados também mencionaram receber dos familiares apoio do tipo ajuda material e de serviço $(n=2)$, que inclui auxílio com trabalhos domésticos, locomoção e outros cuidados. Esse tipo de apoio foi importante no momento do velório do bebê $(n=2)$. 
A satisfação frente ao apoio recebido decorreu da iniciativa dessas pessoas para intermediar conflitos e situações no momento da despedida, ritual de grande importância para a adaptação à perda (Quitans, 2018). Os familiares também foram provedores de apoio emocional $(\mathrm{n}=10)$, que incluiu, além do diálogo, demonstrações de carinho (como abraços e escuta). O diálogo é importante, pois falar sobre a perda ajuda a criar repertórios e estratégias de enfrentamento (Carneiro et al., 2017).

Contudo, em todas as entrevistas foram encontrados relatos de insatisfação com o apoio recebido tanto de familiares quanto de amigos e conhecidos. A insatisfação decorreu da ausência de escuta e/ou tentativas de ajuda pouco confortadoras/acolhedoras (por exemplo, conselhos não solicitados e pressão para superação do luto). Esse desconforto foi sentido por todos os casais em algum momento. A principal queixa foi o não reconhecimento da dor frente à $\mathrm{PG}$, o que acarretou sentimentos de isolamento $\mathrm{e}$ incompreensão $(n=6)$. Essa situação indica o não reconhecimento social do luto (Worden, 2013), mencionado na literatura recente (McGee et al., 2018; Chavez et al., 2019), configurando falta de apoio emocional e de regulação/controle social.

A literatura aponta a PG como um tema complicado a ser tratado por pessoas conhecidas do casal (Quitans, 2018), por não possuírem uma real consciência das implicações dessa perda (Miranda, 2016). Todos os participantes manifestaram uma percepção de que muitas pessoas (inclusive nas relações íntimas) não sabiam o que lhes falar e mostravam-se temerosas em abordar o assunto e magoá-los. Alguns conselhos recebidos de amigos/conhecidos foram avaliados de forma insatisfatória por todos os participantes. Embora buscassem amenizar a dor, causavam angústia, sendo percebidos como negativos. Esses achados concordam com a literatura, que aponta a existência de discursos que desconsideram esses casais como pais, invalidando a existência dos seus filhos (Quitans, 2018). Assim, constatou-se a carência de apoio emocional para os casais, diante da falta de validação social e diálogo (Chavez et. al., 2019; Lemos \& Cunha, 2015; McGee et al., 2018; Quitans, 2018).

Entretanto, os amigos íntimos conseguiram prover um apoio satisfatório para os casais, conforme referido por grande parte deles $(n=8)$. Esses amigos configuram uma rede de relações íntimas e de contato direto, que proveu apoio emocional e companhia social (Sluzki, 2003), reconhecendo o sofrimento dos entrevistados e abrindo espaço para o diálogo. O reconhecimento da perda se mostra crucial para o apoio efetivo (Lemos \& Cunha, 2015). 
Especialmente para as mulheres, uma fonte de apoio importante foram os grupos online $(n=11)$ formados por outras mulheres que também vivenciaram uma PG. A literatura aponta a relevância da participação feminina nesses grupos (Quitans, 2018). No presente estudo esse recurso foi buscado apenas pelas mulheres, mas Chavez et al. (2019) destacaram a necessidade e o desejo dos homens de também compartilhar experiências com pessoas que já vivenciaram situação semelhante. Esses grupos ajudaram as participantes a conhecer outras histórias e a dividir as suas experiências, promovendo o acesso a novos contatos $(n=11)$, ou seja, a comunicação com pessoas que até então não faziam parte da sua rede social (Sluzki, 2003). Esse tipo de apoio permitiu verificar como a PG é um acontecimento bastante frequente e essa descoberta gerou empatia e aceitação por parte das entrevistadas, bem como o sentimento de que elas não eram as únicas a passar por essa situação, como já apontado por outros estudos (Chavez et al., 2019). Entende-se que as entrevistadas $(n=11)$ encontraram apoio emocional e de guia cognitivo/de conselhos nesses grupos virtuais, algo importante para o processo de luto decorrente de uma PG (Carneiro et al., 2017).

A espiritualidade, independentemente da crença, também se mostrou um recurso de apoio importante para todos os casais, mesmo para aqueles que afirmaram não possuir religião. As pessoas ligadas ao meio religioso forneceram majoritariamente apoio emocional $(\mathrm{n}=12)$, a partir de conversas, missas e rezas. Os casais buscaram nessa prática conforto, entendimento e significado para a PG, corroborando estudos recentes (Chavez et al., 2019; Quitans, 2018). A importância dessa prática foi mencionada por todos participantes, que consideraram a religiosidade e a espiritualidade como aliadas. Esse achado concorda com investigações que identificaram uma diminuição da angústia em mulheres com práticas religiosas (Arshad \& Hafeez, 2016). Os casais fortaleceram suas crenças religiosas e o vínculo com membros desse meio a partir dessa experiência positiva, o que contraria parcialmente achados de um estudo norte-americano (McGee et al., 2018), que identificou questionamento da fé e das razões espirituais da perda. Por outro lado, alguns participantes $(\mathrm{n}=2)$ relataram descontentamento quanto às atitudes de pessoas do seu meio religioso. Sluzki (2003) classifica tais relações como comunitárias ou de serviço, por configurar um meio externo de relacionamentos e vínculos eventuais. De fato, essa insatisfação decorreu, segundo os casais, da indisponibilidade de pessoas desse meio, quando acionadas para apoio emocional e guia cognitivo/de conselhos. 
O tratamento psicológico pode fornecer apoio emocional e ajudar no desenvolvimento de estratégias para lidar com a perda (Koert et al., 2018). De fato, a psicoterapia foi percebida como um recurso satisfatório para alguns participantes. A busca desse atendimento foi realizada pelas mulheres após a PG $(n=7)$; apenas um casal realizou terapia em conjunto. Essa atividade caracteriza-se como uma relação comunitária e de serviço, pois a ligação com os profissionais é ocasional (Sluzki, 2003). Embora as mulheres comumente busquem esse recurso, os homens também necessitam desse cuidado (Chavez et al., 2019). Os tipos de apoio recebido dessa fonte foram o emocional $(n=2)$, fornecido a partir do diálogo, bem como ajuda material e de serviço $(n=7)$, em virtude de recomendações, instruções e esclarecimentos desses profissionais acerca da PG. A relevância dessa fonte de apoio para os casais reforça a importância da atuação da Psicologia frente essa demanda (Carneiro et al., 2017).

Outros profissionais de saúde (Medicina e Enfermagem) foram referidos, em alguns casos, pelas percepções positivas de apoio $(n=10)$. Essa percepção positiva se deu em relação a situações pontuais, já que todos os casais também relataram insatisfação com essas fontes. Identificou-se suporte emocional $(n=9)$ e ajuda material/de serviço $(\mathrm{n}=8)$, essa última entendida como colaborações específicas, por meio de explicações e orientações (Sluzki, 2003). O apoio emocional foi oferecido majoritariamente pelo diálogo dos casais com esses profissionais. A humanização foi um fator crucial na comunicação da PG, concordando com a literatura (Lemos \& Cunha, 2015; Quitan, 2018). Entretanto, as falhas no suporte fornecido pelos profissionais foram mais frequentes $(n=12)$, com destaque para a falta de empatia, de humanização, de informação e de orientações, o que concorda com estudos anteriores (Koert et al., 2018; Miranda, 2016). Essa insatisfação foi verificada tanto em relação a serviços públicos quanto privados e foi decorrente da falta de apoio emocional, companhia social e ajuda material e de serviços. Um relato comum entre os participantes foi o descumprimento da Lei do Acompanhante (Lei Federal $n^{\circ} 11.108$, de 07 de abril de 2005), o que se tornou um obstáculo ao apoio do cônjuge, considerado pelo casais como a principal fonte de apoio no momento da PG. A importância desse acompanhamento está explícita nas orientações do Ministério da Saúde (2016) e o seu impedimento repercutiu de maneira negativa na experiência da $\mathrm{PG}(\mathrm{n}=2)$.

A dificuldade de acesso a profissionais de saúde mental durante a internação hospitalar, somada à postura insensível e impessoal de outros profissionais, causou 
sofrimento adicional aos participantes. Tais achados corroboram resultados anteriores (Koert et al., 2018; Miranda, 2016) e parecem apontar a ausência de reconhecimento das implicações e significados deste tipo de perda (Miranda, 2016). Esse reconhecimento é essencial para o fornecimento de suporte adequado (Lemos \& Cunha, 2015). A assistência imediata após a perda tem influências de longo prazo sobre os pais enlutados (Ellis et al., 2016), sendo de extrema importância um cuidado respeitoso e uma atenção clínica de qualidade. Nessa direção, acolher as questões emocionais do casal é imprescindível para facilitar o processo de luto (Lemos \& Cunha, 2015).

Constatou-se, então, um descompasso entre as necessidades dos casais no momento da PG e o suporte fornecido pelos profissionais, o que acarreta um impacto emocional (Koert et al., 2018; Quitans, 2018). Entende-se que lidar com a morte na maternidade pode ser difícil para os profissionais de saúde e que isso pode repercutir no atendimento prestado, como constatado nos depoimentos dos casais. Importante, então, ampliar a discussão sobre essa vivência e as oportunidades de reflexão sobre a prática, para aprimorar o suporte ao processo de luto parental (Carneiro et al., 2017).

Ainda, os casais $(\mathrm{n}=06)$ mencionaram satisfação com o apoio recebido de colegas de trabalho. Segundo Sluzki (2003), as relações profissionais, embora de cunho pessoal, são caracterizadas por menor grau de compromisso. Essas fontes forneceram apoio emocional (em espaços pontuais de conversa no ambiente de trabalho) e regulação/controle social (através da reafirmação de papéis e responsabilidades). Destaca-se que, em algumas empresas, houve a compreensão sobre o momento da perda e foi concedido um período de férias ou mesmo folgas para alguns entrevistados. Entretanto, também foram mencionadas situações em que a PG foi tratada de forma velada no ambiente de trabalho. Essa postura de omissão foi percebida tanto nos colegas quanto nos próprios entrevistados, que, muitas vezes, preferiam não falar sobre o assunto nesses locais. Essa evitação pode ter sido motivada pela falta de reconhecimento da PG, percebida pelos casais em outras instâncias. Essa postura, contudo, repercute no recebimento de apoio nesses ambientes. O descontentamento com o apoio foi acarretado por esse silêncio, pautado na percepção de não ser o local de trabalho um espaço possível para abordar o tema, configurando falta de apoio emocional. Estudos sobre as repercussões da PG no ambiente de trabalho são escassos, embora as relações laborais possam fazer parte da rede de apoio dos indivíduos. 
Por fim, os resultados sugerem a coexistência de percepções de satisfação e insatisfação dos casais frente à mesma fonte de apoio, exceto para o cônjuge e grupos online de mães, que foram sempre avaliados positivamente e destacaram-se como facilitadores para o enfrentamento da PG. Esses achados demonstram, de modo geral, o caráter dinâmico e subjetivo do apoio social. Nos relatos de satisfação dos casais, destacou-se o apoio emocional fornecido por todas as fontes, tipo de suporte já apontado como o mais válido diante situações incontroláveis de estresse, como a perda de uma pessoa próxima (Straub, 2014). Esse tipo de apoio contribuiu para o sentimento de acolhida e o reconhecimento da perda. Ao contrário, relatos de insatisfação decorreram do seu não reconhecimento por diferentes fontes, que não compreenderam o sofrimento da vivência de PG e a necessidade de estabelecer espaços de escuta para os casais nomearem e se permitirem sentir essas emoções, o que repercute no processo de luto (Bellet, Holland, \& Neimeyer, 2018).

Por fim, considerando a entrevista como um todo, cabe ressaltar que a insatisfação com o apoio da rede social foi explanada de forma mais espontânea e extensa pelos casais, ocupando um espaço maior nas suas falas, ao contrário dos aspectos positivos. Isso mostra a importância de avaliar esse construto junto a esses casais para elaborar intervenções.

\section{Considerações finais}

Esse estudo objetivou investigar a percepção de casais que vivenciaram uma PG sobre o apoio social. Particularmente, buscou examinar as fontes de apoio, os tipos de apoio recebido pelos casais e sua satisfação com o mesmo, bem como avaliar o ajustamento conjugal. Constatou-se tanto satisfação como insatisfação em relação às diferentes fontes e tipos de apoio recebidos diante da PG, com exceção do cônjuge, que foi citado de forma unânime como fonte de apoio, e dos grupos online de mães. Em geral, a insatisfação foi mais enfatizada nos relatos, embora restrita a um menor número de fontes. Já no que se refere à satisfação com o apoio, esse referiu-se a situações mais pontuais e foi proveniente de fontes mais variadas, sendo a principal o cônjuge. Esse achado pode ter sido enviesado pela forma de coleta de dados empregada (realização de entrevista conjunta com o casal), que pode ter causado um constrangimento para a exposição de descontentamentos para com o(a) companheiro(a). 
A família, a psicoterapia e a religião também se mostraram como importantes fontes de apoio emocional, ajuda material/de serviço e regulação/controle social. Observou-se, por outro lado, a insatisfação dos casais quanto à invisibilidade do impacto emocional da PG para os profissionais de saúde. Ficou evidente a relevância do apoio emocional para a vivência da PG, tanto para as mulheres quanto para os homens, apesar de haver diferenças de gênero quanto a essas necessidades.

O tema da PG e o seu impacto na vida de quem a sofre vêm recebendo atenção na literatura nacional e internacional, mas poucos estudos avaliaram a perspectiva do casal conjuntamente sobre o apoio recebido. O presente trabalho avança nesse quesito, apresentando resultados que corroboram a literatura da área e que apontam a necessidade de uma mudança social do olhar para a PG, para melhor apoiar aqueles que vivem essa situação, tendo em vista o pouco reconhecimento da dor desta perda e a limitação dos espaços de diálogo sobre as dificuldades desse processo de luto. $\mathrm{O}$ reconhecimento se mostra fundamental para o provimento de apoio satisfatório e a assistência de qualidade, especialmente para o público masculino, ainda pouco escutado e acolhido.

Espera-se que os achados subsidiem intervenções para o fortalecimento da rede de apoio de casais enlutados, já que o apoio social tem sido associado a desfechos positivos nessas situações (Carneiro et al., 2017; Miranda, 2016; Quitans, 2018;). Sugerese a inclusão de discussões sobre o tema entre os profissionais de saúde em espaços de educação permanente, para que possam apoiar de forma mais satisfatória esses casais, dada a complexidade dessa vivência. A inclusão de profissionais de saúde mental nas equipes que lidam com a PG pode auxiliar nesse sentido.

Sugere-se que futuras investigações incluam amostras maiores e mais diversificadas em relação ao nível socioeconômico e à presença de condições específicas do bebê, como as malformações fetais. Da mesma forma, que se direcionem a serviços e profissionais de saúde, pela sua relevância para a saúde mental dos casais e das próprias equipes.

* Projeto com apoio financeiro, na modalidade de Bolsa Produtividade em Pesquisa do CNPq. 


\section{Referências}

Arshad, T., \& Hafeez, N. (2016). Religiosity social support and distress in miscarriage. Pakistan Journal of Professional Psychologists, 7(1) 45-58. Recuperado de http://pu.edu.pk/images/journal/clinicalpsychology/PDF/paper\%204_v7_1_16.pdf

Bellet, B. W., Holland, J. M., \& Neimeyer, R. A. (2018). The Social Meaning in Life Events Scale (SMILES): A preliminary psychometric evaluation in a bereaved sample. Death Studies, 43(2) 1-10. DOI: $\underline{\text { 10.1080/07481187.2018.1456008 }}$

Bellhouse, C., Temple-Smith, M. J., \& Bilardi, J. E. (2018). "It's just one of those things people don't seem to talk about...” women's experiences of social support following miscarriage: a qualitative study. BMC Women's Health, 18(1), 1-9. DOI: $10.1186 / \mathrm{s} 12905-018-0672-3$

Braun, V., Clark, V., Hayfield, N., \& Terry, G. (2019). Thematic Analysis. In Liamputtong, P. (Editor). Handbook of research methods in health social sciences (pp. 843-860). Singapore: Springer. https://doi.org/10.1080/2159676X.2019.1628806

Busby, D. M., Christensen, C., Crane, D. R., \& Larson, J. H. (1995). A revision of the Dyadic Adjustment Scale for use with distressed and non-distressed couples: Construct hierarchy and multidimensional scales. Journal of Marital and Family Therapy, 21(3), 289-308. DOI: https://doi.org/10.1111/j.1752-0606.1995.tb00163.x

Camarneiro, A. P. F., Maciel, J. C. S. C., \& Silveira, R. M. G. da. (2015). Experiencias de la interrupción espontánea del embarazo en primerizas en el primer trimestre gestacional: Un estudio fenomenológico. Revista de Enfermagem Referência, IV(5), 109-117. DOI: http://dx.doi.org/10.12707/RIV14064.

Carneiro, H. L. B., Rodrigues, A. A., \& Alves, M. S. (2017). A dor silenciosa dos pais de filhos natimortos e neonatos. Humanidades, 6(1), 59-71. Recuperado de http://www.revistahumanidades.com.br/arquivos_up/artigos/a129.pdf

Chavez, M. S., Handley, V., Jones, R. L., Eddy, B., \& Poll, V. (2019). Men's experiences of miscarriage: A passive phenomenological analysis of online data. Journal of Loss and Trauma, 1-14. DOI: https://doi.org/10.1080/23802359.2019.1611230

Creswell, J. W. (2010). Projeto de pesquisa: Métodos qualitativo, quantitativo e misto ( $3^{\mathrm{a}}$ ed.). Porto Alegre: Artmed.

Ellis, A., Chebsey, C., Storey, C., Bradley, S., Jackson, S., Flenady, V., ... Siassakos, D. (2016). Systematic review to understand and improve care after stillbirth: A review of 
parents and healthcare professionals' experiences. BMC Pregnancy and Childbirth, 16(1), 1-19. DOI: 10.1186/s12884-016-0806-2.

Gonçalves, T. R., Pawlowski, J., Bandeira, D. R., \& Piccinini, C. A. (2011). Avaliação de apoio social em estudos brasileiros: aspectos conceituais e instrumentos. Ciência \& Saúde 16(3), 1755-1769. DOI: https://doi.org/10.1590/S1413-81232011000300012

Hernandez, J. A. E. (2008). Avaliação estrutural da escala de ajustamento diádico. Psicologia em Estudo, 13(3), 593-601. DOI: https://doi.org/10.1590/S141373722008000300021.

Koert, E., Malling, G. M. H., Sylvest, R., Krog, M. C., Kolte, A. M., Schmidt, L. \& Nielsen, H. S. (2018). Recurrent pregnancy loss: Couples' perspectives on their need for treatment, support and follow up. Human Reproduction, 34(2), 1-16. DOI: 10.1093/humrep/dey362.

Lari L. R., Shimo, A. K. K., Carmona, E. V., De Moraes, M. H. B. L., \& Campos, C. J. G. (2018). Suporte aos pais que vivenciam a perda do filho neonato: Revisão de literatura. Aquichan, 18(1), 80-94. DOI: 10.5294/aqui.2018.18.1.8

Lemos, L. F. S., \& Cunha, A. C. B. (2015). Concepções sobre morte e luto: Experiência feminina sobre a perda gestacional. Psicologia: Ciência e Profissão, 35(4), 11201138. DOI: https://doi.org/10.1590/1982-3703001582014.

Mourão, A. F. S. (2016). Impacto de uma morte fetal ou neonatal nos homens e comunicação do casal acerca da perda: Percepção feminina. Dissertação de Mestrado. Universidade Lusófona de Humanidades e Tecnologias, Lisboa. Recuperado de http://recil.grupolusofona.pt/bitstream/handle/10437/7835/Disserta\%C3\%A7\%C3\% A30\%20Definitiva\%20\%28Ana\%20F\%C3\%ADlipa\%20Mour\%C3\%A3o\%29.pdf?s equence $=1$

Mcgee, K., PettyJohn, M. E., \& Gallus, K. L. (2018). Ambiguous loss: A phenomenological exploration of women seeking support following miscarriage. Journal of Loss and Trauma, 23(6), 1-15. DOI: 10.1080/15325024.2018.1484625

Ministério da Saúde (2016). Diretriz Nacional de Assistência ao Parto Normal. CONITEC. Recuperado de http://conitec.gov.br/images/Consultas/2016/Relatorio_Diretriz-PartoNormal_CP.pdf Miranda, A. C. (2016). Quando a morte antecede o nascimento: Atuação do enfermeiro especialista em saúde materna e obstetrícia na assistência à mulher que vivencia uma 
morte fetal. Relatório de Estágio. Programa de Mestrado em Enfermagem de Saúde Materna e Obstetrícia, Universidade de Évora, Évora, Portugal. Recuperado de http://dspace.uevora.pt/rdpc/bitstream/10174/19521/1/Relat\%c3\%b3rio\%20Ana \%20 Miranda.pdf

Muza, J. C., Sousa, E. N., Arrais, A. R., \& Iaconelli, V. (2013). Quando a morte visita a maternidade: Atenção psicológica durante a perda perinatal. Psicologia: Teoria e Prática, $\quad$ 15(3), 34-48. $\quad$ Recuperado de https://www.researchgate.net/publication/317462639 Quando_a_morte_visita_a_ma ternidade atencao psicologica durante a perda perinatal

Núcleo de Infância e Família - NUDIF. (2008). Ficha de Dados Sociodemográficos. Porto Alegre: Instituto de Psicologia - UFRGS.

Quitans, E. T. (2018). Eu também perdi meu filho: Luto paterno na perda gestacional/neonatal. Dissertação de Mestrado. Programa de Pós Graduação em Psicologia Clínica, Pontifícia Universidade Católica do Rio de Janeiro, Rio de Janeiro. Recuperado de https://www.maxwell.vrac.puc-rio.br/34141/34141.PDF

Rios, T. S, Santos, C. S. S., \& Dell'Aglio, D. D. (2016). Elaboração do processo de luto após uma perda fetal: Relato de experiência. Revista de Psicologia da IMED, 8(1), 98107. DOI: $10.18256 / 2175-5027 /$ psico-imed.v8n1p98-107

Santos, R. C. S., Yamamoto, Y. M., \& Custódio, L. M. G. (2017). Aspectos teóricos sobre o processo de luto e vivência do luto antecipatório. Psicologia.pt. Recuperado de http://www.psicologia.pt/artigos/textos/A1161.pdf

Sluzki, C. E. (2003). A rede social na prática sistêmica: Alternativas terapêuticas (2a ed). São Paulo: Casa do Psicólogo.

Straub, R. O. (2014). Psicologia da Saúde: Uma Abordagem Biopsicossocial. $3^{\text {a }}$ Edição. Editora: Artmed

Vescovi, G., \& Levandowski, D. C. (2017). Vivências de perda gestacional: Um estudo qualitativo sobre resiliência familiar. Projeto de pesquisa não publicado. Porto Alegre.

Vescovi, G. (2018). Perda gestacional: Implicações para as famílias e experiência nos serviços de saúde. Dissertação de Mestrado. Universidade Federal de Ciências da $\begin{array}{lllll}\text { Saúde } & \text { de } & \text { Porto } & \text { Alegre. }\end{array}$ 
https://repositorio.ufcspa.edu.br/jspui/bitstream/123456789/644/3/Gabriela\%20Vesc ovi.pdf

Walsh, F. (2016). Processos normativos da familia: Diversidade e complexidade (4 $\left.{ }^{\mathrm{a}} \mathrm{ed}.\right)$. Porto Alegre: Artmed.

Worden, J. W. (2013). Aconselhamento do luto e terapia do luto: Um manual para profissionais da saúde mental ( $4^{\mathrm{a}}$ ed). São Paulo: Roca.

Submetido em: 02/06/2020

Aprovado em: 11/09/2020 